\title{
THE MAIN STEPS OF THE LEADING PROCESS WITH SPECIAL ATTENTION TO ORGANISING AND COOPERATING AT THE LAW ENFORCEMENT AND MILITARY ORGANIZATIONS
}

\author{
Gábor KOVÁCS \\ National University of Public Service, Budapest, Hungary \\ kovacs.gabor@uni-nke.hu
}

\begin{abstract}
Leading the subordinated uniformed colleagues is a very difficult leadership work. This is a very sophisticated area of the management science. The military and law enforcement leaders (commanders) should know well the steps of the leadership- and management process. The Department of Management Sciences at National University of Public Service is improving the students' leadership skills. The essay leads the readers through the main steps of the leading process, shows the best practice of the Hungarian management sciences. The essay pays special attention to the organising and cooperating work related to the Hungarian law enforcement and military organization. The reader will gain a full insight to the frame of management process, the organising and cooperating work and this experience can be successfully adapted to his own work.
\end{abstract}

Keywords: National University of Public Service, leading process, management process, management, the best practice of Hungarian military and law enforcement organization

\section{Introduction}

The Hungarian military and law enforcement organizations are working effectively in order to solve the different problems. The military and law enforcement leaders should know well the steps of the leadership- and management process [1].

A well-functioning and successful organisation cannot exist without the effective leading staff and the wellorganised leading organisation. The tasks of the leaders are important because they have to prepare to coordinate the management process. The essay pays special attention to the organising and cooperating work

\section{The Realization of Leading Process, in the Law Enforcement and Military Organizations}

The leading functions are very complicated, but they help the leader to manage a successful activity. Occasionally, the leading process is very flexible, because certain management functions can be repeated or returned to the fore. The leading functions used in the law enforcement and military organizations are the following:

1. collecting-, analysing- and using the information

2. planning (making different variations of the decision, preparing the decision)

3. decision making (this is the most important leading function)

4. organizing, coordination (to execute the decision)

5. leading (leading the tasks)

6. controlling and evaluation [2]. 


\subsection{Collecting, analysing and using the information}

The basic condition of the successful leader work is that, the leader always have to have the necessary information in order to manage the organization. In the well-organized information system the leaders are available, they receive internal and external information about the organization. The leaders have to manage and operate the necessary information led by the activity. The process of the information is a very complex task. As a leader we need to select and evaluate the information flood.

1.2. Planning (making the different variations of the decision, preparing the decision)

During the planning process, the leader realizes, who is the responsible person, how can achieve the targets. The law enforcement agencies and the military organizations can use these following planning methods: sequential method, parallel method, and combined working method [3].

\subsection{Decision}

The decision is a management function, where the leader makes some variations and choose one version in order to attain the successful activity.

\subsection{Organizing, coordination (to execute the decision)}

The leader of the organization coordinates and harmonizes the different work methods in order to achieve the specific goals of the organization. This work essentially involves the organization processes, the creation of the new organization and the organization of the different working elements.

The coordination is a well-defined management function where the leader:

1. formulates and plans the followup activities (construction engineering);

2. delivers the information to the subordinates (release provisions);
3. coordinates and organizes the tasks with the subordinate leaders and colleagues;

4. ensures all material and immaterial component which are needed to achieve the goals of the organization.

In the management system it is essential that the leaders deliver the tasks to all subordinate organizations, who will forward them to the subordinates as well. The tasks of the military and law enforcement organizations - according to the cooperation - concentrate to four main areas. These are the following:

\section{Development of organizations:}

- defining organizational goals (legal controls precisely defined),

- ensure the operating conditions,

- through the provision of resources (the last two provides the superior environment)

2. Operation of the processes (basically it is implemented by the co-operation within the organization):

- interpretation of the process points,

- intervention in the operation,

- establishment of an operational structure,

- collection and evaluation through the experience.

3. Representation (internal and external collaboration enforceable): the legal, financial and ethical representation of the organization.

4. Turn off the processes of the external environment: assumes cooperation with external bodies, processes to protect against harmful interference.

1.5. The coordination of tasks of the organization

During the organization process, the leader coordinates the work methods in order to achieve the goals of the organization. This is the essence of the organization's activities. In this process the leader coordinates their cooperation. During the organization (coordination) the 
commander creates a harmony between the organization's body and the available internal and external resources.

\subsection{The release of provisions}

The appearance of provisions can be oral and written. These are prepared according to the regulations of the organizations. These consist of compulsory tasks, orders, decisions for the subordinates. The well-known oral provision is the order, which is the strong wish of the superior. This is compulsory for the all subordinated persons and organizations.

\subsection{Organising the cooperation}

The organising work is a leadership activity, in which the commander harmonizes the activities of the own organization and other agencies according to the aim, task, location, and time of execution of the operation. The organization of cooperation is ensuring that all subordinate commanders understand the same way how to perform the task.

\subsubsection{The forms and forums of the cooperation}

- coordination meeting, where the superior leader coordinates the activity. In this forum the subordinate commanders and the leaders of other organization participating.

\section{- leadership coordination,}

which is lead by the superior leader. During the coordination they coordinate the work of subordinate managers.

- written coordination when the draft regulation will send for all leaders

- committee meetings, during a joint management organization which jointly formed by the order of cooperation.

- cooperation meeting, which coordinates the tasks of external cooperation [4].

\subsubsection{The meetings, coordination, reporting}

The basic tool of the management work is the well prepared professionally deduced meeting.
In these meetings the responsibility of the leader is vital. Can we exactly determine the aim and the goal of the meeting? Can we describe what we can achieve in the meeting? If we cannot determine, we don't need to organise a meeting.

\subsubsection{The functions of a good meeting}

Most of the meetings served the following four basic functions either:
a) News, information

\section{disclosure}

In this kind of meeting we would like to inform our colleagues about the senior management decision. At these meetings the main person is the leader, who spreads the information.

b) Type of exchange meeting

In this type of meeting the participants focusing on the future, the plans and the new ideas. In this forum the leader should ask the participants to gain more perspective and ideas. In this type of meeting they do not need to make the decision, let's get it back later on, leave time to the participants in order to make their own decisions - everyone will be better in case of sensitive cases. One of the good method is the "brainstorming" when the participants bring different ideas, solutions and opportunities in order to go closer to the solution.

The good practice of "brainstorming", it is successful if:

1. We collect (accepted) for all the suggestions (collect them on to the whiteboard).

2. The brainstorming section does not allow anyone to append comments of a proposition.

3. The ideas build on each other the aim of "brainstorming" is to trigger the imagination of the participants.

4. Every idea we noted in (preferably on a board where everyone can see) if select them later, you can remove the negative ideas separately. 
5. Let the participants classify the ideas, so it will begin the problemsolving process.

c) The type of problemsolving meeting

The important thing is to convince our colleagues, if necessary, to solve the problem. It is good to involve them in the decision process because they will have to bear its consequences. These types of meetings should be prepared written materials, which have submitted in advance of the required participants.

These materials will accomplish its goal if it is basically consists of the following: Clearly outline what is the problem, what is the decision situation (What is triggered? Is this a general or specific issue? This is a factual list, a description of the consequences). Explain in previous steps in order to solve the problem and any different circumstances. Add additional background information, which can help to understand and resolve the problem. Sketch the possible variants of the solution, the consequences of each version (advantages and disadvantages).

We ignore the issue of written material in case, if we make a short meeting (2-3 days prior to the meeting).

d) the decision-making meeting

This type of meeting, like the problem-solving type, it has some other peculiarities. The participants should come to a possible decision variants, we have a choice in their preferred version, they are ready to defend it, arguments in support of considering its advantages and disadvantages [5].

\subsection{Leading}

The leading is a management function, when the superior intervenes into the leadership process in order to start and maintain the required level.

\subsection{Controlling}

Controlling is a management function when the leader makes sure where are the inferiors in the executing tasks process, how did they execute that, is it possible to reach the goal.

\subsection{Evaluation of the activity}

During evaluation, the leader strengthens the inferior, whether he made the task good or bad.

\section{Conclusions}

The Management Science is a very important and special subject at the National University of Public Service. This essay payed special attention to the coordination. The reader can realise the importance of the leading process and forums. This knowledge helps the students, because they use their theoretical and practical knowledge in order to solve the different problems. We hope that the future leaders will realize the different problems and they will find the common solutions with their subordinates.

\section{References}

[1] Kovacs-Horvath, Management and organization theory of law enforcement agencies. $240 \mathrm{p}$ Budapest: National University of Public Service, pp. 57-92. (ISBN 9786155305412) (2014).

[2] Gabor Kovacs, The police staff's management practice. 225 p. Budapest: Hungarian Association of Police Science, pp. 141-151.(ISBN 9786155305511) (2014).

[3] Gabor Kovacs, The Problem Solving Management Process and the Best Practise of the National University of Public Service In: Ghiță Bărsan, Gheorge Udeanu, Vasile Căruțaşu (szerk.) The Complex Physiognomy of the International Security Environments. 251 p. Sibiu: "Nicolae Balcescu" Land Forces Academy, pp. 104-113. (ISBN:978-973-153-2158) 2015.

[4] Kovacs-Schweickhardt: Organization and management system of law enforcement agencies Budapest National University of Public Service, pp. 17-56. (ISBN 978-615-5305-79-5) (2014).

[5] Czuprák-Kovacs, Vezetés- és szervezéselmélet. Budapest National University of Public Service pp. 52-62. ISBN 978-615-5344-36-7. (2013) 